\title{
Contributions of precipitation, irrigation and soil water to evapotranspiration in (semi)-arid regions
}

\author{
Juana Paul Moiwo and Fulu Tao* \\ Institute of Geographical Sciences and Natural Resources Research, Chinese Academy of Sciences, Beijing, China
}

\begin{abstract}
Evapotranspiration (ET) is the largest mode of water loss in cultivated (semi)-arid regions. Isolating the fractions of ET contributed by various components of the water budget is critical not only for water resources management, but also for sustainable crop production, food security and social stability. This study quantifies the fractions of ET from precipitation, irrigation and soil water in the North China Plain (NCP) - a major crop production base in China. About 24 consecutive years (288 months) of hydroclimatic data (spanning from January 1985 to December 2008) are used in the study. The data are derived from Global Land Data Assimilation System (GLDAS) input/output products and field-measured data in the region. Error analysis suggests that uncertainties/biases in the data products are low, with good correlations among the data products. In the NCP study area, precipitation is the highest contributor to ET $(39.0 \%, 318.2 \mathrm{~mm})$, followed by soil water $(36.3 \%$, $296.2 \mathrm{~mm}$ ) and then irrigation $(24.7 \%, 201.5 \mathrm{~mm})$. This is respectively the equivalent of $29.7,43.9$ and $66.4 \%$ of average soil water, irrigation and precipitation in the region. Precipitation (as the highest contributor) drives the overall trend, amplitude and phase of ET in the study area. While the contribution of precipitation is highest in the wet summer cropping season, the contributions of irrigation and soil water are highest in the relatively dry spring cropping season. It is vital to devise more efficient ET-reduction strategies to ensure sustainability in water use, food security, ecological protection and social stability in the region and beyond.
\end{abstract}

KEY WORDS $\quad$ evapotranspiration; irrigation; North China Plain; precipitation; soil water

Received 18 November 2013; Revised 8 March 2014; Accepted 14 April 2014

\section{Introduction}

Evapotranspiration (ET) is a critical component of the hydrologic cycle and is the main mode of water loss in cultivated lands (Zhang et al., 2004 Rodell et al., 2004a; Scanlon et al., 2006; Moiwo et al., 2010). As a mode of continuous energy flow across the hydrosphere, atmosphere and biosphere (Gowda et al., 2007; Wang et al., 2012), ET affects virtually every aspect of productivity of the ecosystem (Immerzeel et al., 2010; Evett et al., 2012). Also as a mode of continuous water loss to the atmosphere (Liu et al., 2002; Xu and Chen, 2005), ET is often applied in the calibration of vapour contents of planetary and atmospheric boundary layer (Yepez et al., 2003; Williams et al., 2004). Thus adequate knowledge on ET is critical for sustainable water resources management and balanced water supply among industrial, domestic, ecological and agricultural sectors (Nagler et al., 2007; Moiwo et al., 2011a; Wang et al., 2012).

In dynamic resource environments, ET is critical for accurate predictions of water exchange and crop productivity (Scanlon et al., 2006; Moiwo et al., 2012). However, the estimation of ET is often complicated by heterogeneity

\footnotetext{
* Correspondence to: Fulu Tao, Institute of Geographical Sciences and Natural Resources Research, Chinese Academy of Sciences, 11 Datun Road, Beijing 100101, China. E-mail: Taotaofl@igsnrr.ac.cn
}

of vegetation and difficulties in measuring hydrological processes at comparable scales (Reynolds et al., 2000; Batelaan and De Smedt, 2001). This is even more daunting for dynamic flux periods following precipitation and irrigation, when changes in ET and in soil-canopy conductance can be significant (Gowda et al., 2007; Evett et al., 2012; Wang et al., 2012).

As precipitation and irrigation are the most investigated factors of runoff and recharge (Nagler et al., 2007; Tian et al., 2009; Hu et al., 2010; Han et al., 2012), so also are evaporation and transpiration the most investigated variables of ET (Allen et al., 2007; Moiwo et al., 2010; Wang et al., 2012). However, the contributions of precipitation, irrigation and soil water to ET are relatively less investigated aspects of hydrology (Liu et al., 2002; Wu et al., 2013; Yan and $\mathrm{Wu}, 2014)$. Thus isolating these ET fractions could deepen our knowledge not only on water resources management, but also on current global climatic changes (Rodell et al., 2004b; Moiwo et al., 2011b).

Increasing water storage depletion with intensifying irrigation (Strassberg et al., 2009; Yan and Wu, 2014) is increasingly limiting crop production, food security, economic growth and social stability (Moiwo et al., 2012; Feng et al., 2013). Whereas precipitation adds to water storage, irrigation (especially from groundwater pumping) subtracts from it (Kendy et al., 2003; Yang et al., 2010; Moiwo et al., 2010; Cao et al., 2013). Soil water gained 
from precipitation, irrigation or groundwater could easily be depleted by ET in (semi)-arid regions due to high temperatures (Moiwo et al., 2011a; Wu et al., 2013). Thus in these regions, ET generally exceeds the sum of precipitation and irrigation (Liu et al., 2002; Scanlon et al., 2006; Foster and Perry, 2010). The efficiency of water productivity in developing countries is far below that in the developed world (Ali and Talukder, 2008; Wang et al., 2012; Cao et al., 2013; Yan and Wu, 2014). This is especially true for China (a developing country with over 1.3 billion people), where crop production is driven mainly by flood irrigation with pumped groundwater (Kendy et al., 2003; Moiwo et al., 2010; Yang et al., 2002, 2010).

While short-term hydro-agronomic processes are generally well-documented (Xu and Chen, 2005; Evett et al., 2012), the fate of water following precipitation and irrigation and the subsequent soil water processes remain largely unclear (Tian et al., 2009; Han et al., 2012; Moiwo et al., 2012). Knowledge of the processes of subsurface flow in complex real-world conditions is limited by measurement difficulties and simplifications of model concepts (Ritchie, 1998; Batelaan and De Smedt, 2001; Faria and Bowen, 2003; Rodell et al., 2004a, 2004b; Gowda et al., 2007). Even though simple, cumbersome current hydro-agronomic model parameters expose model data collection and simulation processes to errors (Jones et al., 2003; Yepez et al., 2003; Bastiaanssen et al., 2005; Shu et al., 2006). This again points to the need for developing more efficient ways of accounting for the component fractions of the water budget (Liu et al., 2002; Faria and Bowen, 2003; Williams et al., 2004; Allen et al., 2007; Moiwo et al., 2011b, 2012).

Thus in this study, Global Land Data Assimilation System (GLDAS) data products are used in combination with field data to quantify to contribution of precipitation, irrigation and soil water fractions to ET in North China Plain (NCP) - a heavily populated semiarid region that is a key production base in China (Feng et al., 2013; Yan and $\mathrm{Wu}, 2014)$. GLDAS combines satellite data and Land Surface Models (LSM) to estimate global distributions of land surface states such as soil water, runoff and ET (Rodell et al., 2004b; Hogue et al., 2005). In GLDAS, a vegetation tiling approach is used to simulate sub-grid variabilities of land surface states. While the soil/elevation variables are derived from high-resolution global datasets, the baseline meteorological data, derived from National Oceanic and Atmospheric Administration - Global Data Assimilation System analysis (Rodell et al., 2004b), are forced by bias correction products to guide simulation quality (Berg et al., 2005). GLDAS input/output data products are available in the public domain at http:// gdata1.sci.gsfc.nasa.gov/daac-bin/G3/gui.cgi?instance_id =GLDAS10_M.

Contrary to what is known about the contributions of evaporation and transpiration fractions to ET (Ritchie 1998; Faria and Bowen, 2003; Williams et al., 2004), those of precipitation, irrigation and soil water fractions remain little investigated (Ali and Talukder, 2008; Wu et al., 2013). Thus quantifying the contributions of precipitation, irrigation and soil water fractions to ET in NCP could enhance water productivity in the maize/wheat production system in the region. Increased water productivity is critical for sustainable water resources management, crop production, food security and social stability in the region (Chen et al., 2010). Thus the results of the study will have wider positive implications for the livelihoods of the millions of people in the region and beyond.

\section{Method}

While water for transpiration is abstracted from the soil, precipitation, irrigation and groundwater variously add water to soil. Also whereas precipitation and irrigation could directly evaporate without adding to soil water, soil water adds to groundwater (via gravimetric drainage) in times of excess and takes from it (via capillary rise) in terms of shortage. Soil water could also directly be lost to the atmosphere via evaporation and indirectly via transpiration in a continuous process called evapotranspiration (Batelaan and De Smedt, 2001; Jones et al., 2003; Bastiaanssen et al., 2005; Allen et al., 2007; Moiwo et al., 2012). Also due to the generally deep water table in cultivated (semi)-arid regions (Yang et al., 2002, 2006; Hu et al., 2010; Cao et al., 2013), the fraction of precipitation not lost to ET contributes mainly to soil water storage (Han et al., 2008; Moiwo et al., 2011a; Cao et al., 2012) and/or runoff (Faria and Bowen, 2003; Tian et al., 2009). Similarly, the portion of irrigation not lost to ET contributes to soil water storage (Kendy et al., 2003; Han et al., 2012; Moiwo et al., 2011b). With intensification of groundwater-driven irrigation in cultivated (semi)-arid regions (Rodell et al., 2004a, 2009; Yang et al., 2010), ET generally exceeds precipitation in these regions (Kendy et al., 2004; Foster and Perry, 2010). Under the above hydro-agronomic conditions, soil water balance is used to quantify ET (Ritchie, 1998; Jones et al., 2003; Thorp et al., 2008) as:

$$
\mathrm{ET}=\mathrm{PT}+\mathrm{IR}+\partial \mathrm{SW}-\mathrm{RO}
$$

where ET is evapotranspiration; PT is precipitation; IR is irrigation; RO is runoff; and $\partial \mathrm{SW}$ is change in soil water storage (in a given time step) - all in unit of length and in this case, millimetre $(\mathrm{mm})$. The soil water balance terms in Equation 1 are graphically depicted in the water flux chart in Figure 1.

In this study, soil water is water in the unsaturated zone layer of the soil above the water table while groundwater is water in saturated storage below the water table. In Equation 1, soil water is obtained from field measurements and GLDAS output products for soil water. Precipitation is from rain-gauge measurements and GLDAS input data for precipitation. ET is from field lysimeter measurements and GLDAS output products for ET. While runoff is from GLDAS output products for runoff, irrigation is the county statistics data for the study area (Yang et al., 2010; Cao et al., 2013). The multi-source data use allows for cross-validation, bias correction and high accuracy of the water balance model in Equation 1. 


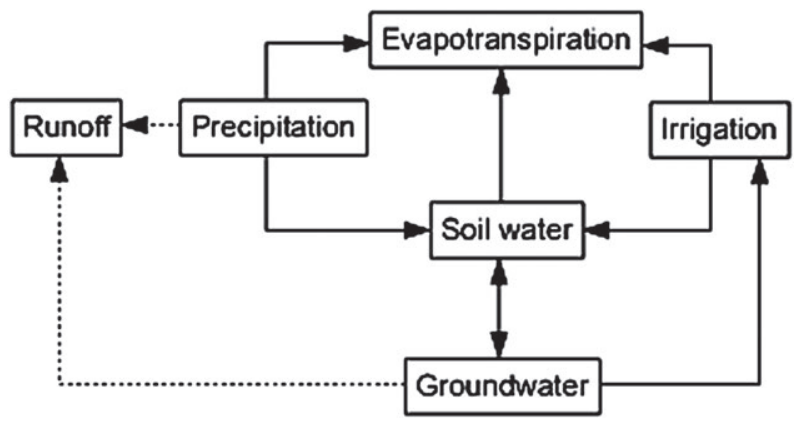

Figure 1. A conceptual flow chart depicting flux flow across the various components of the soil water balance model in Equation (1). Note that evapotranspiration is not quantified for runoff (distinguished by the dotted arrows) because it is considered as water lost from the study area.

Due to limited long-term irrigation measurements, irrigation is not included in GLDAS land surface state simulations (Rodell et al., 2004b). Unlike GLDAS, however, field measurement takes into account the effect of irrigation on soil water. Also unlike GLDAS, lysimeter measurements of ET reflect the sum effect of precipitation, irrigation and soil water (Liu et al., 2002). In other words, GLDAS simulation accounts for only the effects of precipitation and soil water (and not irrigation) on ET (Rodell et al., 2004b). Groundwater recharge also occurs only when soil water exceeds field capacity (Faria and Bowen, 2003). Thus from Equation 1, ET is partitioned into its component fractions (Batelaan and De Smedt, 2001) as:

$$
\mathrm{TT}_{\mathrm{ET}}=\mathrm{PT}_{\mathrm{ET}}+\mathrm{IR}_{\mathrm{ET}}+\mathrm{SW}_{\mathrm{ET}}
$$

where $\mathrm{TT}_{\mathrm{ET}}$ is total ET (derived from lysimeter measurement), $\mathrm{PT}_{\mathrm{ET}}$ is precipitation-driven $\mathrm{ET}, \mathrm{IR}_{\mathrm{ET}}$ is irrigation-driven ET and $\mathrm{SW}_{\mathrm{ET}}$ is ET driven by soil water (when applicable, including capillary rise of groundwater into root-zone soil layer). Note that the transpiration fraction of ET (driven by precipitation and/or irrigation) originates from soil water for land crops. Also field-measured ET (via lysimeter) is the sum effect of ET driven by precipitation, irrigation and soil water (Xu and Chen, 2005; Hoogenboom et al., 1995).

Thus precipitation ET $\left(\mathrm{PT}_{\mathrm{ET}}\right)$ is derived from precipitation (PT), GLDAS soil water storage change $\left(\partial \mathrm{GS}_{\mathrm{SW}}\right)$ and GLDAS runoff $\left(\mathrm{GS}_{\mathrm{RO}}\right)$ as follows:

$$
\mathrm{PT}_{\mathrm{ET}}=\mathrm{PT}+\partial \mathrm{GS}_{\mathrm{SW}}-\mathrm{GS}_{\mathrm{RO}}
$$

Again note that $\partial \mathrm{GS}_{\mathrm{SW}}$ is the change in GLDAS-simulated soil water storage in a given time step, which excludes the effect of irrigation on soil water storage. Whereas it is mostly precipitation that contributes to ET in periods of storage gain, soil water mostly contributes to ET in periods of storage loss (Batelaan and De Smedt, 2001; Hu et al., 2010). This also implies that runoff only occurs under precipitation-driven soil water storage gain. Although water for transpiration originates from soil water, infiltration water during precipitation replaces (often in excess) soil water used in transpiration. This is why farmers generally irrigate under soil water storage loss, during which period runoff is essentially zero.
Thus in computing the irrigation fraction of ET $\left(\mathrm{IR}_{\mathrm{ET}}\right)$, irrigation-driven soil water storage $\left(\mathrm{IR}_{\mathrm{SW}}\right)$ is first calculated from lysimeter-measured soil water storage $\left(\mathrm{FM}_{\mathrm{SW}}\right)$ and GLDAS-simulated soil water storage $\left(\mathrm{GS}_{\mathrm{SW}}\right)$ as:

$$
\mathrm{IR}_{\mathrm{SW}}=\mathrm{FM}_{\mathrm{SW}}-\mathrm{GS}_{\mathrm{SW}}
$$

and $\mathrm{IR}_{\mathrm{ET}}$ is eventually computed as follows:

$$
\mathrm{IR}_{\mathrm{ET}}=\mathrm{IR}-\mathrm{IR}_{\mathrm{SW}}
$$

Further note that in Equation 5, IR is the amount of water used for irrigation. Then the soil water fraction of $\mathrm{ET}\left(\mathrm{SW}_{\mathrm{ET}}\right)$ is the residual of the ET fractions, given as:

$$
\mathrm{SW}_{\mathrm{ET}}=\mathrm{TT}_{\mathrm{ET}}-\mathrm{PT}_{\mathrm{ET}}-\mathrm{IR}_{\mathrm{ET}}
$$

The GLDAS output products used in this study can be replaced with outputs from sufficiently reliable (regional or local) models. Equation 1 can be adjusted to compute the contributions of the fractions of non-negligible components of the soil water balance to ET, making the model flexible for applications in different hydroclimatic and agronomic conditions.

Generally, capillary rise into root-zone soil layer from the layer below is considered to be groundwater. However, the hydrological condition in the NCP study area presents an interesting debate in the water science community (Kendy et al., 2003, 2004; Han et al., 2008, 2012; Foster and Perry, 2010; Cao et al., 2012, 2013). Despite the intensive irrigation or even because of it, there is overall groundwater storage loss of 1-2 m/year in the plain (Yang et al., 2002; Hu et al., 2010; Feng et al. 2013). Excess water (from precipitation and/or irrigation) percolating into the intermediate zone (i.e. the unsaturated zone layer between the root-zone layer and groundwater layer) is hardly enough for field capacity, a prerequisite for groundwater recharge. Thus the intermediate zone is an extension of the unsaturated zone into the layer beneath the root-zone. Under this condition, soil water in the intermediate zone is more responsive to the pull of capillarity (due to suction force of ET) than to the pull of gravity (due to high inter-particle tension). As capillary rise is less than the water needed for healthy and productive crop growth, farmers intensively irrigate in the study area. Also the potential for recharge is remote under the current water use/management practices (Han et al., 2008), thus the continuous water storage depletion in the region.

\section{Application}

\subsection{Study area}

The ET-fraction model above is tested in the NCP study area, a populated semiarid region that is a major grain production base in China. The $140575 \mathrm{~km}^{2}$ NCP study area is bounded by Taihang Mountain on the west, Mongolia Plateau on the north, Yellow River in the south and Bohai Sea in the east (Figure 2). The region has a temperate semiarid monsoon type of climate with wet summers, dry springs and autumns, and snowy winters $\mathrm{Wu}$ 


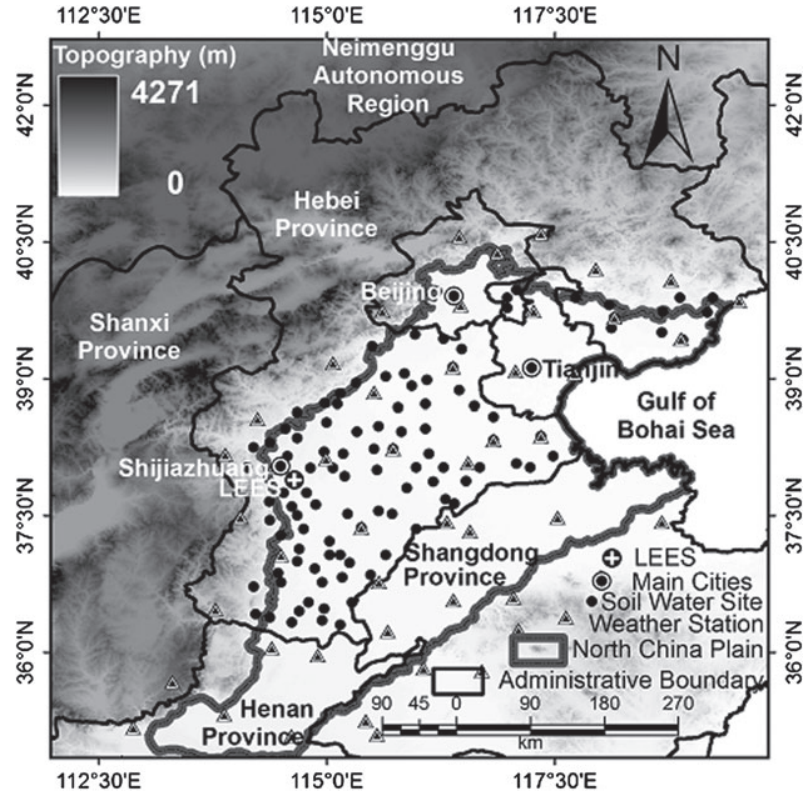

Figure 2. An integrated map of North China Plain, Hebei Province, Beijing and Tianjin depicting the main cities, LEES (Luancheng Eco-agricultural Experimentation Station) site, weather stations and soil water measurement sites. Also shown in the figure is the ambient topography of the North China region.

et al., 2013). The long-term annual average temperature is $12.2^{\circ} \mathrm{C}$, precipitation $479 \mathrm{~mm}$, irrigation $496 \mathrm{~mm}$ and ET $879 \mathrm{~mm}$. Runoff and water storage in the intermediate zone account for the remaining fraction of the water budget (Zhang et al., 2002; Yan and $\mathrm{Wu}, 2014$ ). Also the average depth to water table is $32 \mathrm{~m}$ and groundwater mineral content is less than $0.5 \mathrm{~g} / \mathrm{l}$ (Foster et al., 2004; Kendy et al., 2004; Tamanyu et al., 2009; Hu et al., 2010).

Also the long-term average solar radiation, vapour pressure, relative humidity and wind speed are $524 \mathrm{KJ} / \mathrm{cm}^{2}$, $1.18 \mathrm{kPa}, 38 \%$ and $3.5 \mathrm{~m} / \mathrm{s}$, respectively (Li et al., 2007; Moiwo et al., 2010; Cao et al., 2013). Average soil bulk density in the study area is $1.53 \mathrm{~g} / \mathrm{cm}^{3}$, soil field capacity $22.5 \%$ and tillable-layer soil organic matter content $1.2 \%$ (Yang et al., 2010). Soil texture in the NCP study area is generally sandy-loam, loam and light clay in the upper, middle and lower soil layers, respectively (Han et al., 2008; Chen et al., 2010; Cao et al., 2012). The main cultivated crops are summer maize and winter wheat, but vegetables and fruits have had increasing interests in recent years (Shu et al., 2006; Yang et al., 2010). Because crop production is largely driven by irrigation (Kendy et al., 2003; Yang et al., 2010; Wang et al., 2012; Yan and Wu, 2014), rapid loss of groundwater level threatens sustainable agricultural production in the study area.

Caution should be exercised not to entirely assess the ET-fraction model from the above average fluxes. This is because while precipitation and ET could cover virtually every inch of the study area, irrigation only occurs in cultivated regions. Again whereas ET is a near-continuous process, precipitation and irrigation are intermittent. This implies that ET occurs even without irrigation and could easily exceed precipitation when driven by soil water. Also the fact that not all precipitation or irrigation is lost to ET further underscores the relevance of this study and more so that of the water budget components.

The Luancheng Eco-agriculture Experimental Station (LEES), where the lysimeter measurements are taken, belongs to both the 36 National Ecosystem Observation and Research Network (NEORN) in China and the Global Terrestrial Observation System (GTOS). The 28-ha station is complete with instruments for the measurement of meteorological, hydrological, agricultural and ecological factors, modern laboratories for agro-ecological experiments, and residential blocks for field technicians (Chen et al., 2010). In fact, LEES is the demonstration site for modern agricultural practices in the piedmont region of Mount Taihang, Hebei province (Shu et al., 2006). LEES is located at $37^{\circ} 53^{\prime} \mathrm{N}$ and $114^{\circ} 41^{\prime} \mathrm{E}$ (Figure 2 ) and has an average surface elevation of $50.1 \mathrm{~m}$ above mean sea level (Liu et al., 2002; Cao et al., 2012). Located in the east-west moisture and north-south thermal convergence zone, LEES reflects the regional hydrological, climatic and agronomic conditions across the NCP study area (Kendy et al., 2003).

\subsection{Data acquisition and processing}

Data used in this study include monthly records of precipitation, irrigation, runoff, ET and soil water. The datasets cover 24 consecutive years (288 months), spanning from January 1985 to December 2008. Field data are collected from 42 weather stations for precipitation, 92 monitoring sites for soil water and 1 monitoring site for lysimeter-measured ET (Figure 2).

Strategically, the lysimeter is located in the intersection zone of the east-west moisture and the south-north thermal gradients. The zone has bits of land use, hydrologic, climatic and agronomic conditions across the study area. Thus data collected in the lysimeter station are fairly representative of conditions in the entire NCP (Liu et al., 2002; Cao et al., 2012). Despite this, variables with closely ties to ET (precipitation, temperature, sunshine hour and wind speed) are selected from three other stations (in the distant north, south and east) and analyzed in relation to those at the lysimeter station.

The irrigation data are county statistics averages for the study area (Moiwo et al., 2011a; Yang et al., 2010; Feng et al., 2013). In the weather stations, precipitation is measured by the automatic tipping bucket rain-gauge (Rain Collector II, Davis Inst. Corp., USA), complete with event loggers (HOBO, Onset Comp. Corp., USA) with measurement precision of $0.25 \mathrm{~mm}$. Further details on the precipitation measurement are discussed by Han et al. (2012). The soil water data (gravimetrically taken three times per month) are converted into volumetric soil water content via soil bulk density (Moiwo et al., 2011a).

ET is measured by a large-weighing lysimeter planted at the LEES (Figure 2) experimentation station (Liu et al., 2002, Zhang et al., 2002). The lysimeter dimension is $3 \times 3 \times 2.5 \mathrm{~m}$; and is about 2 ton when empty, 14 ton when filled with soil, and its water-depth precision is $0.02 \mathrm{~mm}$. For the studied 24-year period, treatment conditions at the lysimeter site are assumed to reflect those 

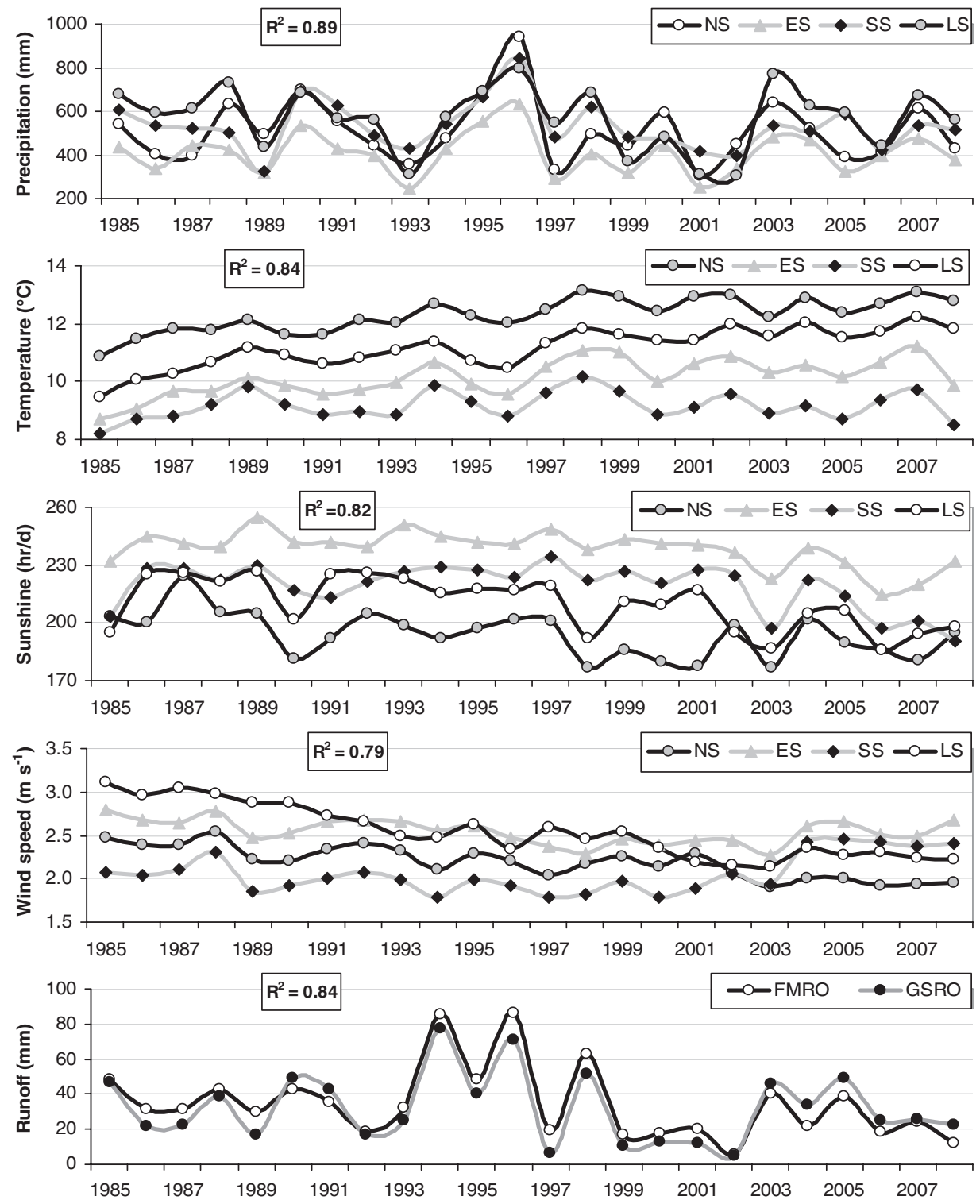

Figure 3. Comparisons of selected ET-related variables from the lysimeter station (LS) with those from three other stations in the distant north (NS), east (ES) and south (SS) of the North China Plain study area. For the ET-plots, $R^{2}$ is the correlation between the variables from LS and the average of the corresponding variables from the other stations. The runoff plot compares field-measured runoff (FMRO) with GLDAS-simulated runoff (GSRO) in the NCP study area.

in across the study area (Liu et al., 2002; Cao et al., 2012). Studies suggest that the climatic variables of precipitation, temperature, wind speed and solar radiation (derivable from sunshine hours, Rietveld, 1978) are significantly related with ET (Ritchie, 1998; Jones et al., 2003; Bastiaanssen et al., 2005; Allen et al., 2007; Thorp et al., 2008; Kjaersgaard et al., 2009). Because ET data are collected from only one lysimeter station, these variables from the lysimeter station are related with those from other three stations in the study area. The plots verify that the lysimeter-measured ET is fairly representative of the study area (Figure 3), further supporting the use of the data. Also independent third-party estimates of ET in the NCP region suggest that ET measurement at the lysimeter station is representative of that in the study area (Moiwo et al., 2010; Wu et al., 2013; Jia et al., 2012 Yan and Wu, 2014).
GLDAS data products (with temporal resolution of 1 month and spatial resolution of one degree) are acquired for precipitation, ET and soil water. GLDAS integrates satellite and field data products in advanced land surface model data assimilation technique to generate optimal fields of global land surface states (Rodell et al., 2004b). GLDAS drives multiple offline (uncoupled with the atmosphere) LSMs, integrates large quantities of field data and simulates high-resolution $\left(0.25-1^{\circ}\right)$ fields using global land information systems (Kumar et al., 2006). LSMs operated by GLDAS include the Mosaic model, Noah model, Community Land Model and Variable Infiltration Capacity model.

GLDAS version- 2 constitutes significant improvements in terms of source code and forcing data, and is therefore reliable for hydrological studies (Rodell et al., 2004a, 2004b). Despite its advanced simulation techniques, 

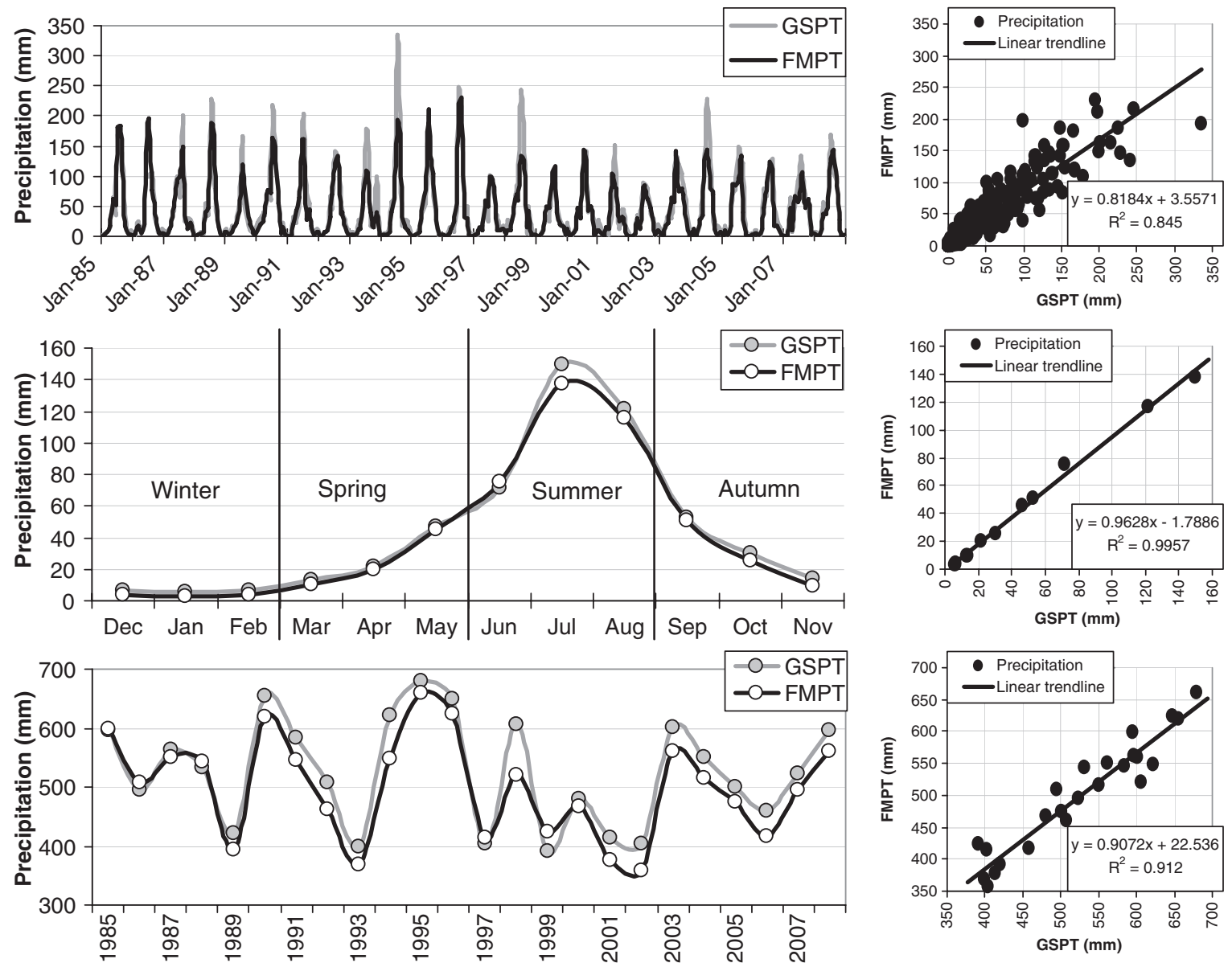

Figure 4. Comparisons of GLDAS input (GSPT) with field-measured (FMPT) precipitation at monthly (top plot), average monthly (middle plot) and annual (bottom plot) scales for the North China Plain study area.

GLDAS, like other models, could not be bias free. As a corrective measure for uncertainty, the averages of the four LSM products are used for the precipitation, ET and soil water variables (Rodell et al., 2009). Then the datasets are processed at the monthly scale in millimetres $(\mathrm{mm})$ of equivalent water. The field-measured data and GLDAS fields are spatially averaged for the $140575 \mathrm{~km}^{2}$ NCP study area and the results presented as time-series and scatter plots.

\subsection{Validation analysis}

Validation is the process of assessing the degree-simulated values match the observed ones within an acceptable range of uncertainty (Thorp et al., 2008). In this study, the range of acceptable uncertainty/bias is set at $10 \%$ of the average value a measured variable. While scatter plots are used as a graphical measure of the model performance, coefficients of determination $\left(R^{2}\right)$ and root mean square errors (RMSE) give mathematical measures of the model. The $R^{2}$ values of the lines of goodness of fit between the field-measured and GLDAS products for precipitation, ET and soil water are annotated on the scatter plots (Figures 3-6), all of which show favourable agreements.

Also bias analysis based on the approach presented by Strassberg et al. (2009) shows average errors in the datasets are within the acceptable $10 \%$ at the 0.05 confidence level. The RMSE between the measured and estimated monthly precipitation, ET and soil water are $11.75,16.81$ and $13.36 \mathrm{~mm}$. As averaging reduces outlier effects, the bias errors could improve at the average monthly and annual scales (Strassberg et al., 2009; Moiwo et al., 2010). This analysis suggests that biases/errors in the datasets, some also discussed by Zhou et al. (2013), have no significant effect on the results of this study.

\section{Results and discussions}

4.1. Precipitation, ET and soil water

Based on the analysis, good correlations generally exist among the GLDAS-simulated and field-measured values of precipitation, ET and root-zone soil water at the monthly, average monthly and annual scales, with $R^{2}$ range of 0.69-0.94 across the scales (Figures 3-6).

While GLDAS input precipitation closely tracks field-measured value in the study area, filed-measured ET and soil water storage are on the average $53 \%$ and $11 \%$ higher than GLDAS-estimated values. The differences in ET and soil water could be due to irrigation, an agronomic operation not incorporated into GLDAS simulation 

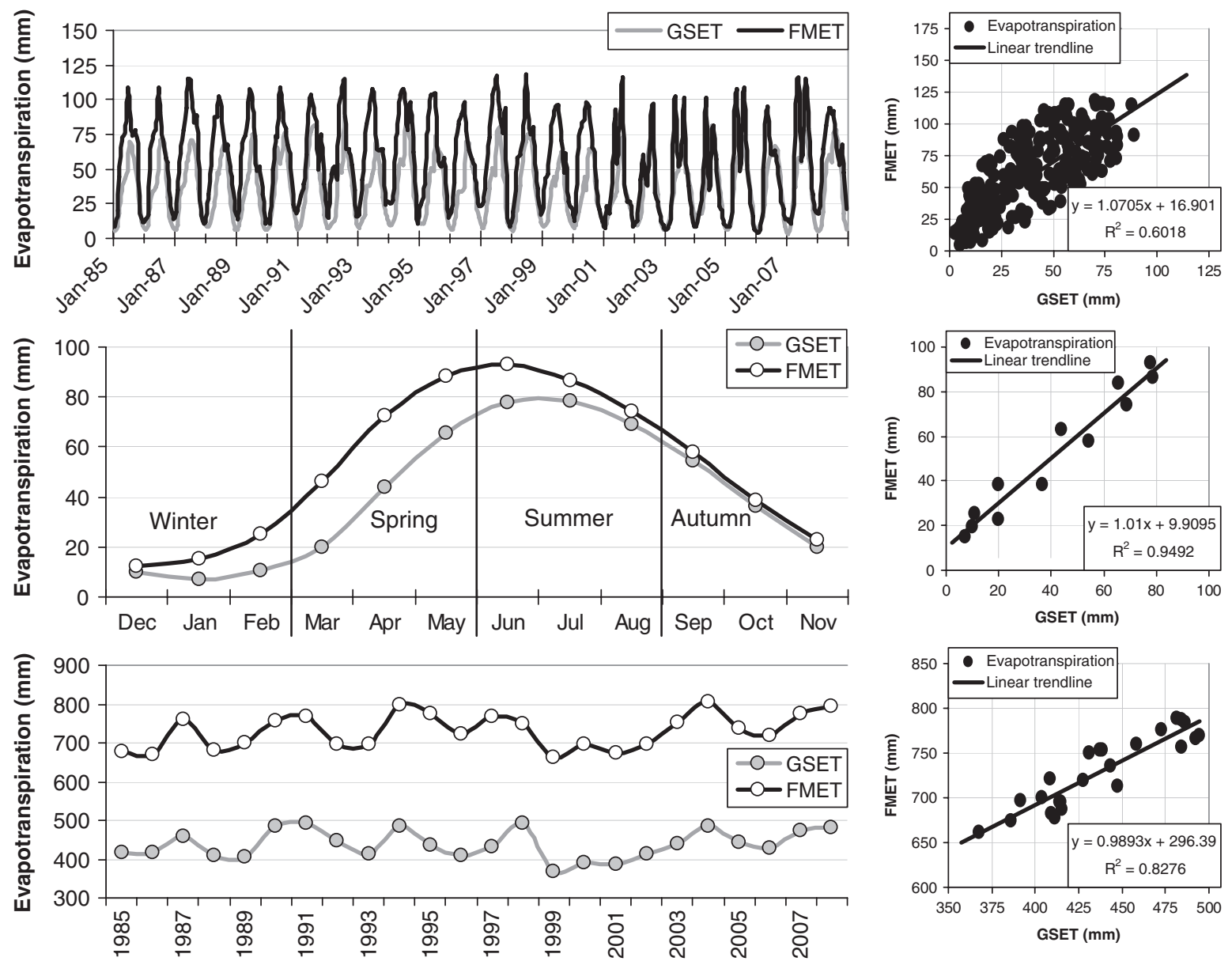

Figure 5. Comparisons of GLDAS-simulated (GSET) with field-measured (FMET) evapotranspiration at monthly (top plot), average monthly (middle plot) and annual (bottom plot) scales for the North China Plain study area.

(Moiwo et al., 2011b). As a major agronomic activity, irrigation is critical for high crop yields in the NCP study area (Liu et al., 2002; Yang et al., 2010; Cao et al., 2013). It is also a major water storage depletion factor in the region (Hu et al., 2010; Wu et al., 2013).

In the study area, precipitation is lowest in winter, increases through spring, peaks in summer and again drops through autumn (Figure 4, middle plot). While the monthly precipitation is lowest in November/December and highest in July/August (Figure 4, top plot), average annual precipitation variation exceeds $300 \mathrm{~mm}$ (Figure 4, bottom plot). Because high variations in annual precipitation could lead to high uncertainties in crop yields under rain-fed agriculture, there is heavy reliance on irrigation in the study area (Kendy et al., 2004; Yang et al., 2006, 2010; Foster and Perry, 2010; Feng et al., 2013).

Although with higher amplitudes, the phases in ET are similar to those in precipitation at the monthly, average monthly and annual scales (Figures 4 and 5). ET is lowest in winter and highest in summer (Figure 5, middle plot). It generally increases from winter through spring, peaks in summer, before again dropping through autumn. While average annual variations in both the field-measured and GLDAS-estimated ET are within $150 \mathrm{~mm}$, field-measured ET is on the average $300 \mathrm{~mm}$ higher than GLDAS-estimated ET (Figure 5, bottom plot). This difference could be due to irrigation, which is not simulated by GLDAS (Rodell et al., 2004b) and some biases in the data products (Zhou et al., 2013). Other studies in the region also note that field-measured ET values (either by lysimeter or neutron probes) are generally higher than model-simulated values (Liu et al., 2002; Kendy et al., 2004; Yang et al., 2010). This also points to difficulties in hydro-agronomic models in accounting for various hydrologic pathways in given regions.

Root-zone soil water variation in the NCP study area is relatively high (Moiwo et al., 2010; Wang et al., 2012). The monthly, average monthly and annual plots in Figure 6 also reflect this trend. Unlike precipitation and ET, soil water storage is lowest in spring, fairly high in winter and autumn, and highest in summer. Also the soil water is generally higher in autumn than in winter (Figure 6 middle plot). In all cases, field-measured soil water is not only higher than GLDAS-estimated soil water, but also not as variable as that of GLDAS. This discrepancy is particularly evident at the annual scale (Figure 6, bottom plot). Whereas GLDAS-estimated soil water accounts for the effects of only precipitation and groundwater, field-measured soil water accounts for the effects of precipitation, irrigation and capillary rise (Hu et al., 2010; 

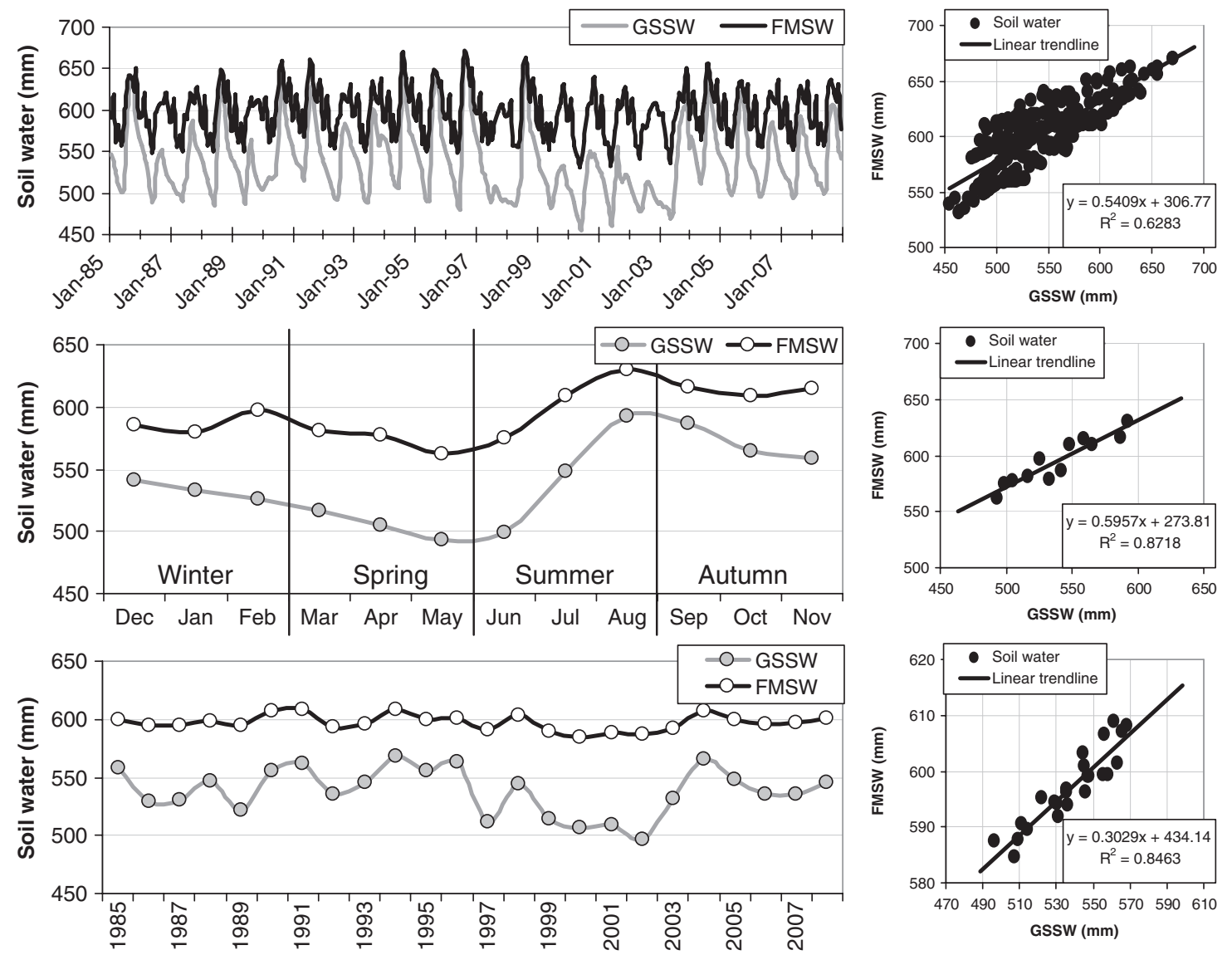

Figure 6. Comparisons of GLDAS-simulated (GSSW) with field-measured (FMSW) root-zone soil water storage at monthly (top plot), average monthly (middle plot) and annual (bottom plot) scales for the North China Plain study area.

Moiwo et al., 2011a). Although sometimes done also in winter (in winter wheat fields), irrigation is highest in spring. Low precipitation during active spring wheat growth period prompts farmers to irrigate more in spring (Liu et al., 2002; Wang et al., 2012; Cao et al., 2013).

\subsection{ET components}

Figure 7 plots the contributions of precipitation, irrigation and soil water to ET in the NCP study area. Also plotted in Figure 7 is the average ET obtained from lysimeter measurement in the LEES station. As the trends in the ET fractions are more distinctive at the average monthly scale (Figure 7, middle plot), further discussions are largely based on this scale. The fractions of ET are lowest in winter, but highest in spring for irrigation and soil water. Similar to precipitation trend, the precipitation fraction of ET is highest in summer.

Irrigation and soil water fractions of ET are fairly low in summer, during which precipitation is highest. In NCP, precipitation mainly occurs in summer; implying that the intensity and frequency of precipitation influence irrigation operations during this season (Yang et al., 2010; Han et al., 2012; Cao et al., 2013). As spring is the driest cultivation season in the NCP study area, high wheat irrigation during the season enhances soil water storage (Kendy et al., 2004; Han et al., 2008; Foster and Perry, 2010; Wang et al., 2012). This is evident in Figure 7 (middle plot) where the contributions of irrigation and soil water to ET are highest during spring season.

In the study area, irrigation contributes $24.7 \%$ $(201.5 \mathrm{~mm})$, soil water $36.3 \%(296.2 \mathrm{~mm})$ and precipitation $39.0 \%(318.2 \mathrm{~mm})$ to ET. This is respectively the equivalent of $29.7,43.9$ and $66.4 \%$ of average soil water, irrigation and precipitation in the region. It then suggests that $70.3 \%(702.4 \mathrm{~mm})$ of the soil water, $56.1 \%$ $(257.5 \mathrm{~mm})$ of the irrigation and $33.6 \%(106.8 \mathrm{~mm})$ of the precipitation contribute to other hydrological pathways in the study area. This could include water storage (as surface water, soil water or groundwater), runoff (surface or sub-surface), discharge to other regions, or consumptions in the domestic and industrial sectors. Based on results from micro-lysimeter experiments, Liu et al. (2002) noted that $30 \%$ of ET in wheat/maize systems in NCP is from soil water evaporation. Thus sound knowledge on the fractions of ET is critical not only for efficient water management, but also for sustainable ecological conditions, crop production and food security in the region.

\section{Conclusions}

In addition to its high population and dry semi-arid climate, the NCP study area remains a major grain production base in China. This study isolates the fractions of ET from precipitation, irrigation and soil water in NCP. 

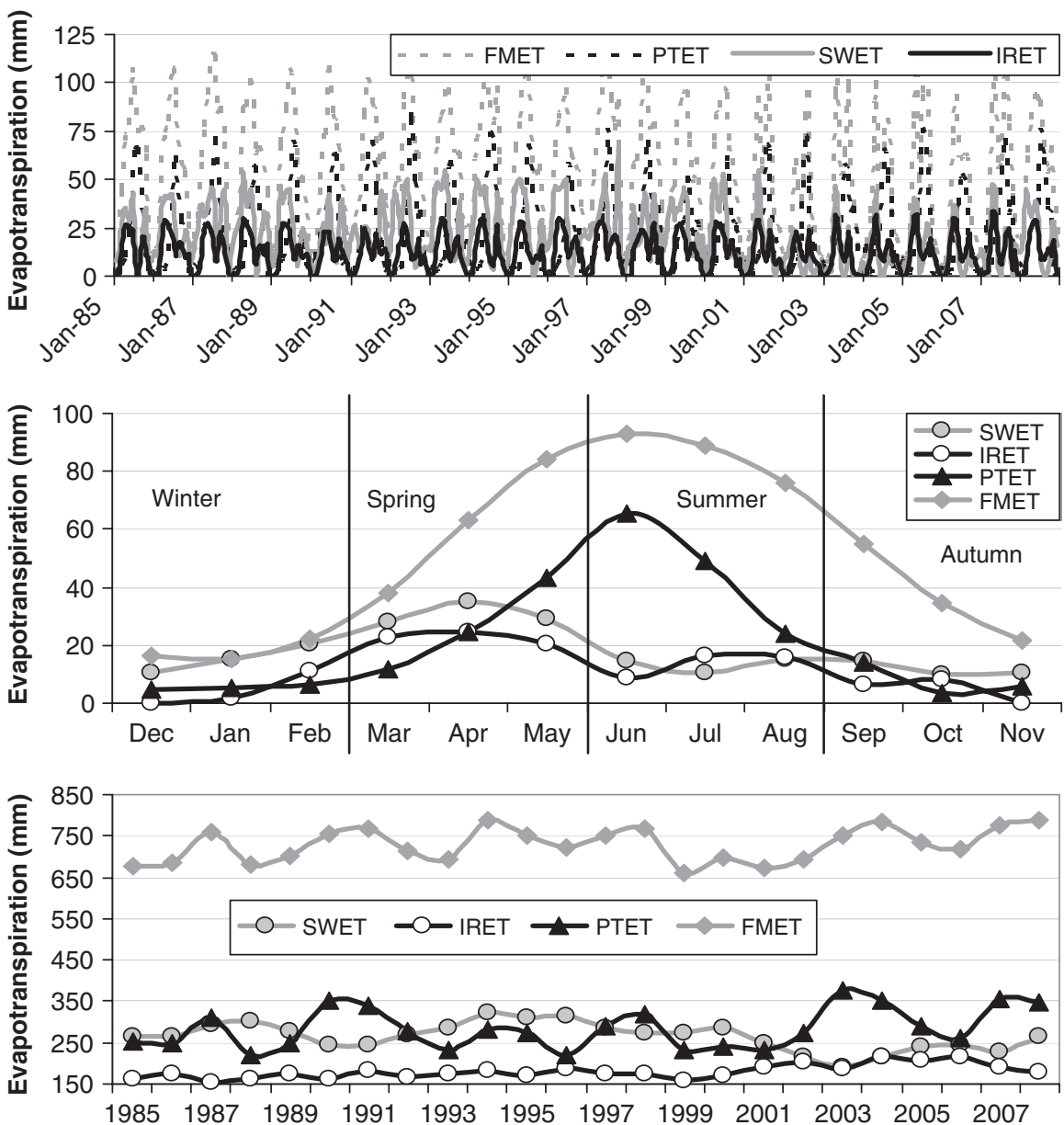

Figure 7. Plots of time-series of precipitation (PTET), irrigation (IRET) and soil water (SWET) components of evapotranspiration along with field-lysimeter-measured (total) evapotranspiration (FMET) at monthly (top plot), average monthly (middle plot) and annual (bottom plot) scales for the North China Plain study area.

About 24 consecutive years or 288 months (spanning from January 1985 to December 2008) of hydro-climatic data are used in the study. The datasets are obtained from GLDAS input/output products and field-measured data. Uncertainty/bias analysis suggests minimal errors in the datasets and good agreements between the field-measured and GLDAS-driven data products at monthly, average monthly and annual scales.

The study shows that precipitation is not only the highest contributor to ET, but also greatly influences the amplitudes and phases of ET in the study area. Because the hydro-climatic processes are generally not in phase with agronomic operations in the region, the component fractions of irrigation and soil water are out of phase with lysimeter-measured ET. In the study area, farmers mainly irrigate in the low precipitation (spring) cropping season. Although soil water storage is highest in summer, its contribution to ET is highest during the low precipitation spring cropping season.

As significant fraction of the precipitation $(66.4 \%)$ is lost to ET, the possibility for precipitation recharge is low in the study area. This explains the continuous storage loss (especially in groundwater storage) in the region. Because precipitation is highest in summer (during which period day length, sunshine hour and temperature are highest), the precipitation fraction of ET is also highest during this period. Since precipitation contributes the most to ET, low precipitations below $479 \mathrm{~mm} /$ year (average value) could impair measures for efficient water management, sustainable crop production and adequate food security in the region.

Irrigation (56.1\% of which is lost to processes other than ET), almost entirely relies on groundwater pumping. Although most of this actually percolates into the soil profile (adding to soil water), it hardly induces groundwater recharge in the study area. This is because irrigation return is not sufficient to meet the water requirements of the intermediate zone soil layer, which is an extension of unsaturated zone into the zone below root-zone soil layer. Thus more efficient strategies are needed to address the negative effects of low precipitation and high irrigation on the scarce water resources, sustainable productivity and the livelihoods of the millions of people in the region.

Efficient water management strategies could ensure sufficient water availability in terms of quantity and quality without significant depletion of (groundwater and/or surface) water resources. Here, efficiency is more about sustainable measures against the depletion of available 
water resources. This could be achieved by ensuring that irrigation models meet the requirements for a balance or equilibrium in water replenishment and utilization. The introduction of more drought-resistant crop varieties (e.g. crops that require less irrigation) is one way to ensure sustainability. Efficient irrigation methods beyond the traditional flooding irrigation could enhance water productivity in the region. Managed aquifer recharge with (treated) wastewaters or reuse of released domestic/industrial waters is another strategy. More innovative uses of brackish water in shallow aquifers could ease pressure on scarce freshwater resources in the region. Direct transfer of water from regions of excess to regions of shortage is another strategy. Recycling of water in industrial and domestic sectors could reduce the rate of tapping into new water resources in the region. Various combinations of different water resources management strategies could as well be useful. Details of these water-wise strategies and several more others are documented in the literature.

\section{Acknowledgements}

This study was supported by the National Key Programme for Developing Basic Science (Project No. 2010CB950902), the National Science Foundation of China (Project No. 41071030), the Strategic Pilot Scientific Projects of Chinese Academy of Science (Project No. XDA05090308) and the Chinese Academy of Sciences Visiting Fellowship for Developing Countries (2013FFZA0019). The GLDAS datasets are curtsies of NASA (National Aeronautics and Space Administration) and the lysimeter and other hydro-climatic datasets are curtsies of LEES, China. We are thankful to the anonymous reviewers and editors for the insightful inputs during the review phase of the manuscript.

\section{References}

Ali MH, Talukder MSU. 2008. Increasing water productivity in crop production - a synthesis. Agric. Water Manage. 95: 1201-1213.

Allen RG, Tasumi M, Trezza R. 2007. Satellite-based energy balance for mapping evapotranspiration with internalized calibration (METRIC)-model. J. Irrig. Drain. E-ASCE 133(4): 380-394.

Bastiaanssen WGM, Noordman EJM, Pelgrum H, Davids G, Thoreson BP, Allen RG. 2005. SEBAL model with remotely sensed data to improve water resources management under actual field conditions. J. Irrig. Drain. E-ASCE 131(1): 85-93, DOI: 10.1061/(ASCE) 0733-9437

Batelaan O, De Smedt F. 2001. WetSpass: a flexible, GIS-based, distributed recharge methodology for regional groundwater modeling. In Impact of Human Activity on Groundwater Dynamics, Gehrels $\mathrm{H}$, Peters J, Hoehn E, Jensen K, Leibundgut C, Griffioen J, Webb B, Zaadnoordijk W-J (eds). IAHS Press: Wallingford, UK; 11-17.

Berg AA, Famiglietti SJ, Rodell M, Reichle RH, Jambor U, Holl SL, Houser PR. 2005. Development of a hydrometeorological forcing data set for global soil moisture estimation. Int. J. Climatol. 25: 1697-1714.

Cao J, Liu C, Zhang W, Han S. 2012. Using temperature effect on seepage variations as proxy for phenological processes of basin-scale vegetation communities. Hydrol. Processes 27: 360-366, DOI: 10.1002/hyp.9231.

Cao G, Zheng C, Scanlon BR, Liu J, Li W. 2013. Use of flow modeling to assess sustainability of groundwater resources in the North China Plain. Water Resour. Res. 49(1): 159-175, DOI: 10.1029/2012WR011899.
Chen C, Wang E, Yu Q. 2010. Modelling the effects of climate variability and water management on crop water productivity and water balance in the North China Plain. Agric. Water Manage. 97: 1175-1184, DOI: 10.1016/j.agwat.2008.11.012.

Evett SR, Schwartz RC, Casanova JJ, Heng LK. 2012. Soil water sensing for water balance, ET and WUE. Agric. Water Manage. 104: 1-9, DOI: 10.1016/j.agwat.2011.12.002.

Faria RT, Bowen WT. 2003. Evaluation of DSSAT soil-water balance module under cropped and bare soil conditions. Braz. Arch. Biol. Technol. 46(4): 489-498.

Feng W, Zhong M, Lemoine J-M, Biancale R, Hsu H-T, Xia J. 2013. Evaluation of groundwater depletion in North China using the Gravity Recovery and Climate Experiment (GRACE) data and ground-based measurements. Water Resour. Res. 49(4): 2110-2118, DOI: $10.1002 /$ wrer 20192.

Foster SSD, Garduno H, Evans R, Olson D, Tian Y, Zhang W, Han Z. 2004. Groundwater-irrigated agriculture on the North China Plain assessing and achieving stability. Hydrogeol. J. 12: 81-93.

Foster SSD, Perry CJ. 2010. Improving groundwater resource accounting in irrigated areas: a prerequisite for promoting sustainable use. Hydrogeol. J. 18: 291-294.

Gowda PH, Ch'́avez JL, Colaizzi PD, Evett SR, Howell TA, Tolk JA. 2007. Remote sensing based energy balance algorithms for mapping ET: current status and future challenges. Am. Soc. Agric. BioEng. 50: 1639-1644.

Han S, Yang Y, Lei Y, Tang C, Moiwo JP. 2008. Seasonal groundwater storage anomaly and vadose zone soil moisture as indicators for precipitation recharge in the piedmont region of Taihang Mountain, North China Plain. Hydrol. Res. 39: 479-495.

Han S, Yang Y, Fan T, Xiao D, Moiwo JP. 2012. Precipitation-runoff processes in Shimen hillslope micro-catchment of Taihang Mountain, north China. Hydrol. Processes 26(9): 1332-1342, DOI: 10.1002/hyp.8233.

Hogue TS, Bastidas L, Gupta H, Sorooshian S, Mitchell K, Emmerich W. 2005. Evaluation and transferability of the Noah land surface model in semiarid Environments. J. Hydrometeorol. 6: 68-84.

Hoogenboom G, Tsuji GY, Pickering NB, Curry RB, Jones JW, Singh U. 1995. Decision support system to study climate change impacts on crop production. In Climate Change and Agriculture: Analysis of Potential International Impacts, Vol. 59, Rosenzweig C (ed). ASA Special Publication: ASA, MA; 51-75.

$\mathrm{Hu}$ Y, Moiwo JP, Yang Y, Han S, Yang Y. 2010. Agricultural water-saving and sustainable groundwater management in Shijiazhuang Irrigation District, North China Plain. J. Hydrol. 393: 219-232, DOI: 10.1016/j.jhydrol.2010.08.017.

Immerzeel WW, van Beek LPH, Bierkens MFP. 2010. Climate change will affect the Asian water towers. Science 328: 1382-1384.

Jia Z, Liu S, Xu Z, Chen Y, Zhu M. 2012. Validation of remotely sensed evapotranspiration over the Hai River Basin, China. J. Geophys. Res. 117(D13): 1984-2012, DOI: 10.1029/2011JD017037.

Jones JW, Hoogenboom G, Porter CH, Boote KJ, Batchelor WD, Hunt LA, Wilkens PW, Singh U, Gijsman AJ, Ritchie JT. 2003. The DSSAT cropping system model. Eur. J. Agron. 18: 235-265.

Kendy E, Gèrard-Marchant P, Walter MT, Zhang Y, Liu C, Steenhuis TS. 2003. A soil-water-balance approach to quantify groundwater recharge from irrigated cropland in the North China Plain. Hydrol. Processes 17: 2011-2031.

Kendy E, Zhang Y, Liu C, Wang J, Steenhuis T. 2004. Groundwater recharge from irrigated cropland in the North China Plain: case study of Luancheng County, Hebei Province, 1949-2000. Hydrol. Processes 18: 2289-2302.

Kjaersgaard JH, Cuenca RH, Martínez-Cob A, Gavilán P, Plauborg F, Mollerup M, Hansen S. 2009. Comparison of the performance of net radiation calculation models. Theor. Appl. Climatol. 98: 57-66, DOI: 10.1007/s00704-008-0091-8.

Kumar SV, Peters-Lidard CD, Tian Y, Houser PR, Geiger J, Olden S, Lighty L, Eastman JL, Doty B, Dirmeyer P, Adams J, Mitchell K, Wood EF, Sheffield J. 2006. Land information system - an interoperable framework for high resolution land surface modeling. Environ. Model. Softw. 21: 1402-1415.

Li X, Hu C, Delgado JA, Zhang Y, Ouyang Z. 2007. Increased nitrogen use efficiencies as a key mitigation alternative to reduce nitrate leaching in north China plain. Agric. Water Manage. 89: 137-147, DOI: 10.1016/j.agwat.2006.12.012.

Liu C, Zhang X, Zhang Y. 2002. Determination of daily evaporation and evapotranspiration of winter wheat and maize by large-scale weighing lysimeter and micro-lysimeter. Agric. For. Meteorol. 111: 109-120.

Moiwo JP, Yang Y, Xiao D, Yan N, Wu B. 2010. Comparison of ETWatch-estimated evapotranspiration with that from combined 
GRACE and precipitation measurement data in Hai River Basin, North China. Hydrol. Sci. J. 56(2): 249-267, DOI: 10.1080/02626667.2011. 553617.

Moiwo JP, Tao F, Lu W. 2011a. Estimating soil moisture storage change using quasi-terrestrial water balance method. Agric. Water Manage. 102: 25-34, DOI: 10.1016/j.agwat.2011.10.003.

Moiwo JP, Yang Y, Tao F, Lu W, Han S. 2011b. Water storage change in the Himalayas from the Gravity Recovery and Climate Experiment (GRACE) and an empirical climate model. Water Resour. Res. 47: W07521, DOI: 10.1029/2010WR010157.

Moiwo JP, Tao F, Lu W. 2012. Analysis of satellite-based and in situ hydro-climatic data depicts water storage depletion in North China Region. Hydrol. Processes 27(7): 1011-1020, DOI: 10.1002/hyp.9276.

Nagler PL, Glenn EP, Kim H, Emmerich W, Scott RL, Huxman TE, Huete AR. 2007. Relationship between evapotranspiration and precipitation pulse in a semiarid rangeland estimated by moisture flux towers. J. Arid Environ. 70: 443-462.

Reynolds JF, Kemp PR, Tenhunen JD. 2000. Effects of long-term rainfall variability on evapotranspiration and soil water distribution in the Chihuahuan desert: a modeling analysis. Plant Ecol. 150: 145-159.

Rietveld MR. 1978. A new method for estimating the regression coefficients in the formula relating solar radiation to sunshine. Agric. Meteorol. 19: 243-252.

Ritchie JT. 1998. Soil water balance and plant water stress. In Understanding Options for Agricultural Production, Vol. 6, Tsugi GY, Hoogen-boom G, Thornton PK (eds). Kluwer Academic Publishers: Dordrecht, The Netherlands; 41-54.

Rodell M, Famiglietti JS, Chen J, Seneviratne SI, Viterbo P, Holl S, Wilson CR. 2004a. Basin scale estimates of evapotranspiration using GRACE and other observations. Geophys. Res. Lett. 31: L20504, DOI: 10.1029/2004GL020873.

Rodell M, Houser PR, Jambor U, Gottschalck J, Mitchell K, Meng CJ, Arsenault K, Cosgrove B, Radakovich J, Bosilovich M, Entin JK, Walker JP, Lohmann D, Toll D. 2004b. The global land data assimilation system. Bull. Am. Meteorol. Soc. 85: 381-394.

Rodell M, Velicogna I, Famiglietti JS. 2009. Satellite-based estimates of groundwater depletion in India. Nature 460: 999-1002.

Scanlon BR, Kelley EK, Alan LF, Lorraine EF, Cheikh BG, Edmunds WM, Ian S. 2006. Global synthesis of groundwater recharge in semiarid and arid regions. Hydrol. Processes 20: 3335-3370.

Shu Y, Lei Y, Zheng L, Li H. 2006. An evapotranspiration (ET) mode based GIS using LANDSAT data and MODIS data with improved resolution. Proc. SPIE 6366: 63661N-63669N.

Strassberg G, Scanlon BR, Chambers D. 2009. Evaluation of groundwater storage monitoring with the GRACE satellite: case study of the High Plains aquifer, central United States. Water Resour. Res. 45: W05410, DOI: 10.1029/2008WR006892.

Tamanyu S, Muraoka H, Ishii T. 2009. Geological interpretation of groundwater level lowering in the North China Plain. B Geologic. Surv. Jpn. 60: 105-115.
Thorp KR, Jaynes DB, Malone RW. 2008. Simulating the long-term performance of drainage water management across the Midwestern United States. Trans. ASABE 51(3): 961-976.

Tian F, Yang Y, Han S. 2009. Using runoff slope-break to determine dominant factors of runoff decline in Hutuo River Basin, North China. Water Sci. Technol. 60: 2135-2144.

Wang P, Song X, Han D, Zhang Y, Zhang B. 2012. Determination of evaporation, transpiration and deep percolation of summer corn and winter wheat after irrigation. Agric. Water Manage. 105: 32-37, DOI: 10.1016/j.agwat.2011.12.024.

Williams DG, Cable W, Hultine K, Hoedjes JC, Yepez EA, Simonneaux V, Er-Raki S, Boulet G, De BH, Chehbouni A, Hartogensis OK, Timouk F. 2004. Evapotranspiration components determined by stable isotope, sap flow and eddy covariance techniques. Agric. For. Meteorol. 125: 241-258.

Wu B, Jiang L, Yana N, Perry C, Zeng H. 2013. Basin-wide evapotranspiration management: concept and practical application in Hai Basin, China. Agric. Water Manage., DOI: 10.1016/j.agwat.2013. 09.021 .

Xu C-Y, Chen D. 2005. Comparison of seven models for estimation of evapotranspiration and groundwater recharge using lysimeter measurement data in Germany. Hydrol. Processes 19: 3717-3734, DOI: 10.1002/hyp. 5853

Yan N, Wu B. 2014. Integrated spatial-temporal analysis of crop water productivity of winter wheat in Hai Basin. Agric. Water Manage. 133: 24-33.

Yang Y, Watanabe M, Sakura Y, Tang C, Hayashi Y. 2002. Groundwater table and recharge changes in piedmont region of Taihang Mountain in North China Plain and its relation to agricultural water use. Water SA 28: $171-178$.

Yang Y, Watanabe M, Zhang X, Zhang J, Wang Q, Hayashi S. 2006. Optimizing irrigation management for wheat to reduce groundwater depletion in the piedmont region of the Taihang Mountains in the North China Plain. Agric. Water Manage. 82: 25-44.

Yang Y, Yang Y, Moiwo JP, Hu Y. 2010. Estimation of irrigation requirement for sustainable water resources reallocation in North China. Agric. Water Manage. 97: 1711-1721.

Yepez EA, Williams DG, Scott R, Lin G. 2003. Partitioning overstory and understory evapotranspiration in a semi-arid savanna ecosystem from the isotopic composition of water vapor. Agric. For. Meteorol. 119: $53-68$.

Zhang Y, Liu C, Shen Y, Kondoh A, Tang C, Tanaka T, Shimada J. 2002. Measurement of evapotranspiration in a winter wheat field. Hydrol. Processes 16(14): 2805-2817.

Zhang Y, Kendy E, Yu Q, Liu C, Shen Y, Sun H. 2004. Effect of soil water deficit on evapotranspiration, crop yield, and water use efficiency in the North China Plain. Agric. Water Manage. 64: 107-122, DOI: 10.1016/S0378-3774(03)00201-4.

Zhou X, Zhang Y, Yang Y, Yang Y, Han S. 2013. Evaluation of anomalies in GLDAS-1996 dataset. Water Sci. Technol. 67(8): 1718-1727, DOI: $10.2166 /$ wst.2013.043. 